\title{
Evaluation of the BD GeneOhm MRSA Real-time PCR Assay for Detection of Nasal Colonization by MRSA
}

\author{
Hee Jin Huh ${ }^{1}$, Eu Suk Kim², Seok Lae Chae ${ }^{1}$ \\ ${ }^{1}$ Department of Laboratory Medicine, Dongguk University Ilsan Hospital, Goyang, \\ ${ }^{2}$ Department of Internal Medicine, Seoul National University Bundang Hospital, Seongnam, Korea
}

Background: Methicillin-resistant Staphylococcus aureus (MRSA) is a major nasocomial pathogen. The active surveillance of MRSA is essential to limit its transmission. The BD GeneOhm MRSA real-time PCR assay (Becton Dickinson Diagnostics, San Diego, USA) has been recently developed and used for same-day MRSA detection directly from nasal swab specimens. The authors of the present study compared GeneOhm MRSA PCR with culture methods to evaluate its diagnostic performance for MRSA active surveillance.

Methods: The present study was conducted on patients admitted to the ICU for six months. A total of 371 nasal swab specimens were obtained from patients at admission day and at the seven-day follow-up. The swab was streaked onto culture media, and presumptive $S$. aureus colonies were confirmed as MRSA using the BD Phoenix automated microbiology system (Becton Dickinson Diagnostic Systems, Sparks, USA). In addition, GeneOhm MRSA PCR was performed. For discrepant results between GeneOhm MRSA PCR and culture, the enrichment broth culture method was performed.
Results: There were 34 samples with discrepant results between the GeneOhm MRSA PCR and culture. The overall agreement was $90.7 \%$. For the detection of MRSA, the GeneOhm MRSA PCR was $96.8 \%$ sensitive and $86.3 \%$ specific, with positive and negative predictive values of $83.9 \%$ and $97.3 \%$, respectively.

Conclusion: Identification of MRSA-colonized patients was achieved in as little as two hours, and the high negative predictive value of GeneOhm MRSA PCR suggests that the assay is a rapid method for the identification of persons who are not colonized with MRSA. However, due to the low positive predictive value, GeneOhm MRSA PCR combined with enrichment culture in cases of positive GeneOhm MRSA PCR is potentially useful for active MRSA surveillance activities. (Korean J Clin Microbiol 2011;14: 74-78)

Key Words: Methicillin-resistant Staphylococcus aureus, BD GeneOhm MRSA real-time PCR assay, Active surveillance

\section{서 론}

입원환자가 보균한 메티실린 내성 황색포도알균(methicillinresistant Staphylococcus aureus, MRSA)은 감염의 주요 원인일 뿐 아니라 다른 환자에게 전파가 가능하기 때문에 병원감염과 관련이 있다[1]. 또한, MRSA는 병원비 증가와 직접적인 연관 이 있어, MRSA 보균자를 적극적으로 찾아내고 탈집락화시키 는 것은 세계적으로 중요한 문제로 대두되고 있다[2,3]. 국내에 서도 MRSA에 대한 능동감시의 필요성이 인식되어 일부 대학 병원에서는 능동감시체계를 도입하여 효과적으로 관리를 하고

Received 12 August, 2010, Revised 25 October, 2010

Accepted 25 October, 2010

Correspondence: Seok Lae Chae, Department of Laboratory Medicine, Dongguk University Ilsan Hospital, 814 Siksa-dong, Ilsandong-gu, Goyang 411-773, Korea. (Tel) 82-31-691-7890, (Fax) 82-31-6917902, (E-mail) rocky@dumc.or.kr
있다.

비강내 MRSA 보균 유무를 확인하는 표준 방법은 $6.5 \% \mathrm{NaCl}$ 증균배지 배양이지만, 이 방법은 최소 48 72시간 이상의 시간 이 소요되기 때문에 MRSA 보균 유무의 빠른 선별이라는 목적 에는 부합되지 않는다[4]. 고식적인 동정 방법보다 빠르고 간편 하게 MRSA를 동정할 수 있는 BBL CHROMagar MRSA (Becton Dickinson Diagnostics, Sparks, USA) 등의 선택배지가 유용하게 이용되고 있지만, 이 방법도 결과를 보고하기까지는 24 48시간이 걸린다[5]. 최근 비강도말검체로 직접 실시간중 합효소연쇄반응을 시행하여 결과 보고까지의 시간을 단축시켜 빠른 대처를 가능하게 하는 BD GeneOhm MRSA real-time PCR assay (Becton Dickinson Diagnostics, San Diego, USA; GeneOhm MRSA PCR)가 소개되었다. GeneOhm MRSA PCR 은 Staphylococcal cassette chromosome mec (SCCmec)와 orf $X$ 연결부위에 특이적인 시발체를 이용하여 $\mathrm{MRSA}$ 를 확인하는 
검사이다[6].

저자들은 중환자실 입원환자 중 MRSA 보균자를 선별하기 위해 비강도말 검체를 채취하여 GeneOhm MRSA PCR 및 배 양을 시행하고, 그 결과를 비교하여 MRSA 능동감시에 있어서 GeneOhm MRSA PCR 검사가 임상적 유용성이 있는지 평가 하고자 하였다.

\section{재료 및 방법}

\section{1. 대상}

2009 년 5 월부터 10 월까지 6 개월간 중환자실 환자의 입원 당 시와 입원기간 내 일주일에 한 번씩 채취한 비강도말검체 371 예를 대상으로 하였다. 면봉(BBL CultureSwab, Becton Dickinson Diagnostic Systems, Sparks, USA) 하나를 각각의 전비공에 삽입하여 비강도말검체를 채취하였다. 비강도말검체는 $5^{\circ} \mathrm{C}$ 에 서 냉장보관 후 24 시간 이내에 배양을 시행하였고, 배지 접종 이 끝난 면봉은 48시간 이내에 GeneOhm MRSA PCR과 증균 배양을 시행하였다.

\section{2. 일반배양 후 동정과 항균제 감수성 검사}

비강도말면봉을 blood agar plate와 mannitol salt agar 배지에 접종한 후 $5 \% \mathrm{CO}_{2}, 35^{\circ} \mathrm{C}$ 에서 24 시간 배양하였다. 집락 형태를 확인하여 황색포도알균이 의심되는 경우는 Phoenix SMIC/ ID-100 panel (Becton Dickinson Diagnostic Systems, Sparks, USA) 및 Phoenix Automated Microbiology System (Becton Dickinson Diagnostic Systems, Sparks, USA)을 이용하여 동정 및 항균제감수성검사를 시행하였다.

\section{GeneOhm MRSA PCR assay}

GeneOhm MRSA PCR은 제조사의 지침에 따라 시행하였다. DNA 추출 및 $\mathrm{PCR}$ 시약혼합의 과정을 거쳐 SmartCycler (Cepheid, Sunny Vale, USA)에 장착한 후 PCR을 시행하였다.

GeneOhm MRSA PCR GeneOhm MRSA PCR 결과가 판독 불가(undetermined)인 경우는 추출된 DNA로 GeneOhm MRSA $\mathrm{PCR}$ 검사를 재시행하였다. 재검사하여도 판독불가인 경우는 결과 분석에서 제외하였다.

\section{4. 증균배양}

$6.5 \% \mathrm{NaCl}$ 이 첨가된 tryptic soy broth 증균배지에 $\mathrm{GeneOhm}$ MRSA PCR 검사를 시행하기 위해 MRSA 검체완충튜브(Becton Dickinson Diagnostics, San Diego, USA)에 면봉을 푼 현탁 액 $100 \mu \mathrm{L}$ 를 접종하였다. 일반배양 결과와 GeneOhm MRSA $\mathrm{PCR}$ 결과의 차이를 보이는 경우는 24 시간 후 증균배지를 확인 하였다. 증균배지에 균의 성장이 있는 경우는 blood agar plate 와 mannitol salt agar 배지에 접종하여 계대배양하였다. 황색포 도알균이 의심되는 집락이 형성된 경우는 catalase 검사와 co- agulase 검사를 이용해 황색포도알균을 동정하였고, oxacillin disk를 이용하여 MRSA임을 확인하였다.

\section{5. 결과 분석}

GeneOhm MRSA PCR 결과와 일반배양 결과가 차이를 보이 는 경우는 일반배양 결과 및 증균배양 결과를 종합하여 최종배 양 결과를 도출하였다. 일반배양 음성 또는 양성, 증균배양 양 성인 경우는 최종배양 양성으로 판정하였고, 일반배양 음성, 증 균배양 음성인 경우는 최종배양 음성으로 판정하였다. 최종배 양을 기준으로 양성률, 민감도, 특이도, 음성예측률, 양성예측 률을 산출하였다.

최종배양을 기준으로 한 MRSA 양성률과 GeneOhm MRSA $\mathrm{PCR}$ 을 기준으로 한 양성률을 산출하였다.

\section{결 과}

GeneOhm MRSA PCR 결과 18예는 판독불가였으며, 재검에 서 14예는 결과를 얻을 수 있었고 4예는 연속 판독 불가여서 이 4예는 결과분석에서 제외하였다. 중환자실 환자의 비강내 MRSA 보균율은 최종배양 결과를 기준으로 $42.5 \%$ (156/367)였 고, GeneOhm MRSA PCR 결과를 기준으로 49.5\% (180/367)였 다.

GeneOhm MRSA PCR과 일반배양 결과의 차이를 보이는 61 예에 대해 증균배양을 시행한 결과 27 예는 일반배양 MRSA 음 성이었으나 증균배양에서 MRSA가 동정되어 최종배양 결과는 MRSA 양성으로 판정하였다.

GeneOhm MRSA PCR과 최종배양 결과의 차이를 보이는 예 는 34예로, GeneOhm MRSA PCR 결과와 최종배양 결과의 일

Table 1. Comparison of GeneOhm MRSA PCR and culture

\begin{tabular}{|c|c|c|c|c|c|c|}
\hline & \multicolumn{3}{|c|}{$\begin{array}{l}\text { Results of directly } \\
\text { plated culture }\end{array}$} & \multicolumn{3}{|c|}{$\begin{array}{l}\text { Final results } \\
\text { determined after } \\
\text { enrichment culture }\end{array}$} \\
\hline & Positive & Negativ & Total & Positive & Negative & Total \\
\hline \multicolumn{7}{|l|}{$\begin{array}{l}\text { No. of specimens } \\
\text { tested by Gene- } \\
\text { Ohm MRSA PCR }\end{array}$} \\
\hline Positive & 124 & 56 & 180 & 151 & 29 & 180 \\
\hline Negative & 5 & 182 & 187 & 5 & 182 & 187 \\
\hline Total & 129 & 238 & 367 & 156 & 211 & 367 \\
\hline Sensitivity $(95 \% \mathrm{CI})$ & \multicolumn{3}{|c|}{$96.1 \%(92.8 \sim 99.4)$} & \multicolumn{3}{|c|}{$96.8 \%(94.0 \sim 99.6)$} \\
\hline Specificity $(95 \% \mathrm{CI})$ & \multirow{2}{*}{\multicolumn{3}{|c|}{$\begin{array}{l}76.5 \%(71.1 \sim 81.9) \\
68.9 \%(62.1 \sim 75.7)\end{array}$}} & \multirow{2}{*}{\multicolumn{3}{|c|}{$\begin{array}{l}86.3 \%(94.0 \sim 99.6) \\
83.9 \%(78.5 \sim 89.3)\end{array}$}} \\
\hline $\begin{array}{l}\text { Positive predictive } \\
\text { values }(95 \% \mathrm{CI})\end{array}$ & & & & & & \\
\hline $\begin{array}{l}\text { Negative predictive } \\
\text { values }(95 \% \mathrm{CI})\end{array}$ & \multicolumn{3}{|c|}{$97.3 \%(95.0 \sim 99.6)$} & \multicolumn{3}{|c|}{$97.3 \%(95.0 \sim 99.6)$} \\
\hline
\end{tabular}

Abbreviation: CI, confidence interval. 
치도는 90.7\%였다. GeneOhm MRSA PCR의 민감도는 $96.8 \%$ (95\% confidence interval [CI], 94.0 99.6), 특이도는 86.3\% (95\% CI, 82.3 91.5)였고, 양성예측률은 $83.9 \%$ (95\% CI, 78.5 89.3), 음성예측률은 97.3\% (95\% CI, 95.0 99.6)였다(Table $1)$.

\section{고 찰}

본 연구 결과 6개월간 중환자실 환자의 비강내 MRSA 보균 율은 최종배양을 기준으로 42.5\% (156/367)였고, GeneOhm MRSA PCR을 기준으로 49.5\% (180/367)였다. 이는 중환자실 입원 환자를 대상으로 24시간 이내에 MRSA 감시배양을 시행 한 2007년 연구 결과인 비강내 양성률 $11.6 \%$ 보다 높은 결과였 다[7]. 이 차이는 검사방법에 의한 차이 이외에도 기간 또는 지 역적인 차이로 인한 환자군의 차이일 수도 있으므로, 국내 중 환자실 환자의 비강내 MRSA 보균율을 파악하기 위해서는 여 러 병원을 포함하는 대규모 연구가 필요할 것이다.

비강내 MRSA 보균 유무를 확인하는 표준방법은 $6.5 \% \mathrm{NaCl}$ 증균배지 배양에서 MRSA를 동정하는 것으로, 유럽에서도 선 택 증균배지 배양 후 고체 배지에 접종하여 동정과 항균제 감 수성 검사를 통해 MRSA를 확인하는 것을 표준방법으로 제시 하고 있다[8]. 차이를 보이는 결과를 확인하기 위해 증균배양을 이용하는 다른 연구와 같은 방법으로[5,9], 본 연구에서도 GeneOhm MRSA PCR와 일반배양 결과의 차이를 보이는 61예 에 대해 증균배양을 시행하였다. 그 결과 27예는 일반배양 MRSA 음성이었으나 증균배양에서 MRSA가 동정되어 증균배 양의 필요성을 보여주었다. 그러나, 능동감시를 위해서는 빠른 환자 선택과 격리가 필요하다는 것을 감안하면 민감도가 높은 장점만으로 48 72시간이 소요되는 증균배양을 MRSA 감시를 위한 검사법으로 이용하는 데는 한계가 있다. 이에, 3 4시간 이내에 결과를 확인할 수 있는 multiplex PCR법 및 real time $\mathrm{PCR}$ 법이 개발되고 있고[10], $\mathrm{PCR}$ 검사를 MRSA 감시에 이용 하여 MRSA 전파율을 감소시킨 예들이 보고되고 있다[11]. 평 가를 시행한 GeneOhm MRSA PCR은 검사소요 시간이 2시간 으로 짧아 신속한 환자 격리가 가능하다고 판단되었다.

MRSA 감시를 위한 검사는 MRSA를 보균하고 있는 모든 환 자를 확인함을 목적으로 하기 때문에 높은 민감도와 높은 음성 예측률을 가지는 것이 바람직하다. GeneOhm MRSA PCR의 민감도와 음성예측률은 연구자 및 비교대상에 따라 다양한 결과 를 보여주고 있는데, 민감도는 $85.8 \sim 100 \%$, 음성예측률은 93.5 $\sim 100 \%$ 였다 $[5,9,12,13]$. 본 연구 결과 중환자실 환자의 비강내 MRSA 보균율은 최종배양을 기준으로 $42.5 \%$ 였고 GeneOhm MRSA PCR의 민감도는 96.8\% (151/156), 음성예측률은 $97.3 \%$ (182/187)였다. 음성예측률이 $93.5 \%$ 로 낮아 유병률이 높은 지 역에서 임상적으로 이용하기에는 확인이 필요하다는 국내의
타 연구와 비교하면 본 연구에서는 음성예측률이 $97.3 \%$ 로 높 아 유병률이 높은 상황에서도 비교적 유용하게 이용할 수 있다 고 생각되었다[12].

본 연구에서 GeneOhm MRSA PCR의 특이도는 $86.3 \%$ (182/ $211)$ 였고, 양성예측률은 $83.9 \%$ (151/180)였다. GeneOhm MRSA PCR 양성, 최종배양 음성인 29예 중 14예는 메티실린 감수성 황색포도알균(methicillin-susceptible Staphylococcus aureus, MSSA)이 동정되었다. 저자들은 MSSA 집락으로 직접 GeneOhm MRSA PCR 검사를 시행해 보지는 않았지만, GeneOhm MRSA PCR 양성이고 배양에서 MSSA가 동정된 32예의 집락 으로 GeneOhm MRSA PCR을 시행하여 16예에서 양성으로 확 인한 Paule 등의 연구가 위양성의 원인을 설명해 주고 있다[9]. 불완전한 $m e c A$ 유전자 또는 $\mathrm{PCR}$ 의 target인 $\mathrm{SCCmec}$ 구역은 보존되어 있지만 그 왼쪽의 나머지 기능적인 역할을 하는 $m e c A$ 부분의 결실이 낮은 특이도의 원인으로 보고되고 있다 [14,15]. 다른 논문들에서도 지적되었듯이 MRSA 감시를 목적 으로 GeneOhm MRSA PCR를 시행할 경우 낮은 특이도와 양 성예측률 때문에 필요 없이 많은 환자를 격리하거나 치료하여 비용의 증가를 초래할 수 있으므로, PCR 양성 검체에 대해서 는 본 연구에서 이용한 방법으로 증균배양 결과를 확인하는 것 이 도움이 될 것으로 예측된다.

대상 검체 371 예 중 GeneOhm MRSA PCR에서 18예가 판독 불가였지만, 냉동-해동 후 재검으로 14 예는 결과를 얻을 수 있 었으므로 최종 $1.1 \%$ (4예)가 판독불가였다[16]. 재검에서도 판 독불가인 경우는 검체 내 $\mathrm{PCR}$ 저해물질이 그 원인일 것으로 추정할 수 있었다. 냉동-해동 방법을 이용하여 PCR 저해물질 에 의한 저해율을 $0 \sim 0.9 \%$ 로 낮춘 것으로 보고되어 있다[16]. Paule 등에 의하면 검사자의 기술적인 요인이 검사결과에 영향 을 끼쳐 검사를 시작한 달에는 $4.5 \%$ 의 판독불가 결과를 얻었지 만, 검사가 숙련된 후 1 년간의 총 판독불가율은 $1.7 \%$ 로 낮아졌 고 이 중 재검을 통해 $80 \%$ 는 결과를 얻을 수 있었다[9]. 실제로 환자검체에 GeneOhm MRSAPCR법을 적용할 때, $1 \%$ 이내의 판독불가 검체에 대해서는 증균배양으로 재검사를 시행할 수 있으므로 병원에서 검사로 이용하는데 큰 문제는 없을 것으로 생각된다.

결론적으로, GeneOhm MRSA PCR은 특이도와 양성예측률 이 높지 않고 $1 \%$ 가량의 판독불가 검체가 발생하는 문제가 있 는 반면에 짧은 검사소요시간 및 비교적 높은 음성예측률을 갖 는다는 장점이 있었다. 그러므로, GeneOhm MRSA PCR 양성 예와 판독불가 예에 한해 증균배양법으로 확인검사를 시행한 다면 GeneOhm MRSA PCR을 MRSA 감시배양에 유용하게 이 용할 수 있을 것으로 생각된다. 


\section{참 고 문 헌}

1. von Eiff C, Becker K, Machka K, Stammer H, Peters G. Nasal carriage as a source of Staphylococcus aureus bacteremia. Study Group. N Engl J Med 2001;344:11-6.

2. Wertheim HF, Vos MC, Boelens HA, Voss A, VandenbrouckeGrauls CM, Meester MH, et al. Low prevalence of methicillinresistant Staphylococcus aureus (MRSA) at hospital admission in the Netherlands: the value of search and destroy and restrictive antibiotic use. J Hosp Infect 2004;56:321-5.

3. Cosgrove SE, Qi Y, Kaye KS, Harbarth S, Karchmer AW, Carmeli Y. The impact of methicillin resistance in Staphylococcus aureus bacteremia on patient outcomes: mortality, length of stay, and hospital charges. Infect Control Hosp Epidemiol 2005;26:166-74.

4. Safdar N, Narans L, Gordon B, Maki DG. Comparison of culture screening methods for detection of nasal carriage of methicillinresistant Staphylococcus aureus: a prospective study comparing 32 methods. J Clin Microbiol 2003;41:3163-6.

5. Farley JE, Stamper PD, Ross T, Cai M, Speser S, Carroll KC. Comparison of the BD GeneOhm methicillin-resistant Staphylococcus aureus (MRSA) PCR assay to culture by use of BBL CHROMagar MRSA for detection of MRSA in nasal surveillance cultures from an at-risk community population. J Clin Microbiol 2008;46:743-6.

6. Stamper PD, Cai M, Howard T, Speser S, Carroll KC. Clinical validation of the molecular BD GeneOhm StaphSR assay for direct detection of Staphylococcus aureus and methicillin-resistant Staphylococcus aureus in positive blood cultures. J Clin Microbiol 2007;45:2191-6.

7. Kim OS, Yoon SW, Kang YJ, Kim YK, Lee NY, Lee JH, et al. Rate of nasal colonization of methicillin-resistant staphylococcus aureus at admission to a medical intensive care unit. Korean $\mathbf{J}$ Nosocomial Infect Control 2007;12:42-9.

8. Brown DF, Edwards DI, Hawkey PM, Morrison D, Ridgway GL, Towner KJ, et al. Joint Working Party of the British Society for Antimicrobial Chemotherapy; Hospital Infection Society; Infection
Control Nurses Association Guidelines for the laboratory diagnosis and susceptibility testing of methicillin-resistant Staphylococcus aureus (MRSA). J Antimicrob Chemother 2005;56:1000-18.

9. Paule SM, Hacek DM, Kufner B, Truchon K, Thomson RB Jr, Kaul KL, et al. Performance of the BD GeneOhm methicillinresistant Staphylococcus aureus test before and during high-volume clinical use. J Clin Microbiol 2007;45:2993-8.

10. de San N, Denis O, Gasasira MF, De Mendonça R, Nonhoff C, Struelens MJ. Controlled evaluation of the IDI-MRSA assay for detection of colonization by methicillin-resistant Staphylococcus aureus in diverse mucocutaneous specimens. J Clin Microbiol 2007;45:1098-101.

11. Cunningham R, Jenks $P$, Northwood J, Wallis M, Ferguson S, Hunt S. Effect on MRSA transmission of rapid PCR testing of patients admitted to critical care. J Hosp Infect 2007;65:24-8.

12. Park SH, Jang YH, Sung H, Kim MN, Kim JS, Park YJ. Performance evaluation of BD GeneOhm MRSA PCR assay for detection of nasal colonization of methicillin-resistant Staphylococcus aureus at endemic intensive care units. Korean J Lab Med 2009; 29:439-47.

13. Boyce JM and Havill NL. Comparison of BD GeneOhm methicillin-resistant Staphylococcus aureus (MRSA) PCR versus the CHROMagar MRSA assay for screening patients for the presence of MRSA strains. J Clin Microbiol 2008;46:350-1.

14. Huletsky A, Giroux R, Rossbach V, Gagnon M, Vaillancourt M, Bernier M, et al. New real-time PCR assay for rapid detection of methicillin-resistant Staphylococcus aureus directly from specimens containing a mixture of staphylococci. J Clin Microbiol 2004;42: 1875-84.

15. Donnio PY, Oliveira DC, Faria NA, Wilhelm N, Le Coustumier A, de Lencastre H. Partial excision of the chromosomal cassette containing the methicillin resistance determinant results in methicillinsusceptible Staphylococcus aureus. J Clin Microbiol 2005;43:4191-3.

16. Bischof LJ, Lapsley L, Fontecchio K, Jacosalem D, Young C, Hankerd R, et al. Comparison of chromogenic media to BD GeneOhm methicillin-resistant Staphylococcus aureus (MRSA) PCR for detection of MRSA in nasal swabs. J Clin Microbiol 2009;47:2281-3. 
$=$ 국문초록=

\title{
비강내 메티실린 내성 황색포도알균 검출 검사인 BD GeneOhm MRSA Real-time PCR Assay 평가
}

\author{
${ }^{1}$ 동국대학교 일산병원 진단검사의학과, ${ }^{2}$ 분당서울대병원 내과 \\ 허희진 ${ }^{1}$, 김의석 $^{2}$, 채석래 $^{1}$
}

배경: 병원감염의 주요 원인균인 메티실린 내성 황색 포도알균(methicillin-resistant Staphylococcus aureus, MRSA) 능동감 시는 MRSA 전파를 막기 위해 중요하다. 최근 비강도말검체에서 직접 MRSA 유무를 검사하여 검사당일 결과보고가 가 능한 BD GeneOhm MRSA real-time PCR assay (Becton Dickinson Diagnostics, San Diego, USA; GeneOhm MRSA PCR)가 소개되었다. 이에 저자들은 MRSA 능동감시에 있어서 GeneOhm MRSA PCR 검사가 임상적으로 유용한지를 평가하기 위해 PCR 결과와 배양 결과를 비교하였다.

방법: 연구 기간은 6 개월이었으며, 중환자실 환자의 입원 당시 및 입원기간 내 일주일에 한 번씩 면봉으로 채취한 비강도 말검체 371예를 대상으로 하였다. 검체 배양 후 황색포도알균이 의심되는 경우는 BD Phoenix Automated Microbiology System (Becton Dickinson Diagnostic Systems, Sparks, USA)으로 MRSA임을 확인하였다. 제조사의 지침에 따라 GeneOhm MRSA PCR을 시행하였다. GeneOhm MRSA PCR 결과와 배양 결과가 불일치할 때는 증균 배양 결과를 확인하였다. 결과: GeneOhm MRSA PCR과 최종배양 결과의 차이를 보이는 예는 34예로, GeneOhm MRSA PCR 결과와 최종배양 결과 의 일치도는 $90.7 \%$ 였다. 배양과 비교한 민감도는 $96.8 \%$, 특이도는 $86.3 \%$ 였고, 양성예측률은 $83.9 \%$, 음성예측률은 $97.3 \%$ 였다.

결론: GeneOhm MRSA PCR 검사는 검사소요시간이 2시간으로 짧고, $97.3 \%$ 의 높은 음성예측률을 보여 MRSA를 보균하 지 않은 환자를 빠르게 찾아내는 것이 가능하였다. 그러나, 양성예측률이 높지 않으므로 양성예는 증균배양을 이용하여 확인검사를 시행한다면 GeneOhm MRSA PCR을 MRSA 감시배양에 유용하게 이용할 수 있을 것으로 생각된다. [대한임 상미생물학회지 2011:14:74-78]

교신저자 : 채석래, 411-773, 경기도 고양시 일산동구 식사동 814 동국대학교 일산병원 진단검사의학과

Tel: 031-961-7890, Fax: 031-961-7902

E-mail:rocky@dumc.or.kr 